\title{
Análise da divergência genética entre acessos de Manihot esculenta (Crantz) via caracteres morfoagronômicos
}

\author{
Huan Hernandes RAMOS ${ }^{1}$, Danilo de Lima GONÇALVES ${ }^{1 *}$, Marilene da Silva CASTRO ${ }^{1}$, \\ Maro Antonio Aparecido BARELLI ${ }^{1}$
}

\author{
${ }^{1}$ Departamento de Agronomia, Universidade do Estado de Mato Grosso, Cáceres, MT, Brasil. \\ *E-mail: dlg_net@hotmail.com
}

Recebido em setembro/2017; Aceito em setembro/2018.

RESUMO: Este estudo teve como objetivo avaliar a diversidade genética entre acessos tradicionais de mandioca da coleção da Universidade do Estado de Mato Grosso - UNEMAT, através de caracteres morfoagronômicos. A coleção está localizada na Empresa Matogrossense de Pesquisa, Assistência e Extensão Rural (EMPAER) de Cáceres. Foram utilizados 21 acessos para a avaliação dos caracteres morfoagronômicos: comprimento do lóbulo foliar; largura do lóbulo foliar; comprimento do pecíolo; altura de plantas; altura da primeira ramificação; comprimento das raízes; diâmetro da raiz; peso da raiz; contagem do número de polpas sadias por planta; número de raízes; peso em água; matéria seca e teor de amido. A análise de dissimilaridade foi baseada na Distância Euclidiana e o agrupamento pelo método Hierárquico UPGMA. Os resultados obtidos com o uso de características morfoagronômicas e da Distância Euclidiana dos 21 acessos de mandioca da coleção da UNEMAT evidenciaram a existência de variabilidade genética, onde a maior similaridade ocorreu entre os acessos Rondônia e N.I. 10 - 0501, e a maior divergência entre os acessos Sinop e Liberatão 0507.O Grupo I alocou o maior número de acessos pelo UPGMA e a característica altura média da primeira ramificação foi determinante na formação do Grupo IV. Os acessos analisados apresentaram divergência genética, onde os descritores analisados foram suficientes para a diferenciação dos acessos, onde os NI 02-2816, Poupa Branca e Sinop foram os mais promissores como parentais para cruzamentos entre os demais acessos.

Palavras-chave: produção de mandioca, coleção de germoplasma, variabilidade genética.

\section{Analysis of genetic divergence among Manihot esculenta (crantz) access via morphoagronomic traits}

\begin{abstract}
This study aimed to evaluate the genetic diversity among accessions of traditional cassava collection at the University of Mato Grosso - UNEMAT through morphoagronomic traits. The collection is located in Mato Grosso Company Research, Assistance and Rural Extension (EMPA) of Cáceres. We used 21 accessions for the evaluation of morphoagronomic traits: length of the leaf lobe; lobe leaf width; length petiole; plant height; height of first branching; length of roots; diameter of the root; root weight; counting the number of healthy pulps per plant; number of roots; weight in water; dry matter and starch content. The dissimilarity analysis was based on Euclidean distance and hierarchical clustering method UPGMA. The results obtained with the use of morphoagronomic traits and the Euclidean distance of 21 cassava accessions from the collection of UNEMAT showed the existence of genetic variability, where the greatest similarity was between the Rondônia and N.I. 10 - 0501, and the greatest divergence among the accessions Sinop and Liberatão 0507. The Group I allocated the highest number of accesses by UPGMA and the characteristic height of the first branch was instrumental in the formation of Group IV. The analyzed accessions presented genetic divergence, where the descriptors analyzed were sufficient for the differentiation of the accesses where NI 02-2816, Poupa Branca and Sinop were the most promising as parental for crossings between the other accessions.
\end{abstract}

Keywords: cassava production, germplasm collection, genetic variability.

\section{INTRODUÇÃO}

A mandioca (Manihot esculenta (Crantz) é o segundo alimento com maior fonte de amido, sendo superado apenas pela cultura do milho. É uma cultura altamente versátil, cultivada por pequenos agricultores em mais de 100 países. As raízes são ricas em hidratos de carbono, enquanto as suas folhas tenras contêm até $25 \%$ de proteína, além de ferro, cálcio e vitaminas A e C (FAO, 2013). A mandioca de mesa, também conhecida como mandioca mansa, doce, aipim ou macaxeira é um dos alimentos preferenciais na mesa do brasileiro (CONCEIÇÃO; CRUZ, 1983). Esta constitui uma das mais importantes fontes de carboidratos empregada na alimentação humana, animal e na indústria.

De acordo com dados da FAO (2016), o Brasil obteve uma produção de 21,082 milhões de toneladas de mandioca, ocupando o terceiro lugar na produção mundial, perdendo apenas para a Nigéria e Tailândia. Para Amaral et al., (2007), a produtividade da mandioca se encontra abaixo do seu potencial produtivo, provocado principalmente por práticas incorretas no manejo da cultura.

O plantio e a industrialização ocorrem em todas as regiões do Brasil, adaptando ao sistema de cultivo praticado, 
favorecido pelo baixo custo de produção e ao uso mínimo de tecnologias. Nos últimos anos, a região do Cerrado, grande produtora de grãos do Brasil, vem atraindo a instalação de grandes fecularias e, como consequência, o cultivo de mandioca de indústria vem se profissionalizando na região, levando ao aumento da demanda por variedades de mandioca de indústria específicas para a região e com maior qualidade e potencial produtivo (VIEIRA et al., 2013).

No cultivo de subsistência observa-se a presença de uma grande diversidade de genótipos cujo potencial de utilização é desconhecido. Tornando essa carência de informações referentes à caracterização e à nomenclatura dos genótipos que são plantadas pelos pequenos agricultores, em um dos maiores problemas inerentes à cultura da mandioca para o consumo in natura (SOUZA; FIALHO, 2003). Segundo Zuin et al., (2009), a grande variabilidade genética da espécie predominante na agricultura de subsistência ("fundo-dequintal") é frequente a ocorrência de problemas com a nomenclatura das mesmas. Estudo realizado por Vendramini et al., (2011), demonstram que, entre genótipos de acessos de mandioca coletados na região de Cáceres e Rosário Oeste evidenciam a existência de variabilidade genética.

Para Costa et al., (2003) a importância da mandioca, sob o ponto de vista genético, nesse sistema de agricultura está relacionada com a presença de inúmeras variedades por roça, sendo importante fonte de diversidade genética, principalmente para características específicas, os quais não são encontradas nos materiais melhorados.

Os acessos de mandioca do Brasil estão distribuídos em sete bancos ativos de germoplasma regionais, localizados na Amazônia (Oriental e Ocidental), Tabuleiros Costeiros, Semiárido, Cerrados, Subtrópico e em Campinas-SP. Apesar da reconhecida variabilidade genética existente nesses bancos, o germoplasma de mandioca tem sido pouco estudado, sob o ponto de vista genético. É importante conhecer a maneira como essa variabilidade está distribuída, pois é essencial o conhecimento da estrutura genética, uma vez que, os padrões de distribuição da variabilidade genética estão correlacionados com o sistema reprodutivo, favorecendo a manutenção da variabilidade genotípica, quando estes são devidamente caracterizados e avaliados (ABREU et al., 2008).

Para Yamamoto (2006) as características relacionadas à produção vegetal estão condicionadas ao controle genético do organismo, ao ambiente em que é cultivado e à interação entre esses dois fatores. Por conta disso, diferentes respostas fenotípicas frente às mudanças nas condições ambientais resultam em comportamentos distintos dos genótipos, caracterizando a interação.

Os descritores agronômicos consistem de caracteres com mais baixa herdabilidade, embora desejáveis sob o ponto de vista do produtor. Ambos devem contribuir para visualizar, de uma forma preliminar, a adaptação do material e seu potencial produtivo, pondo em evidência genótipos promissores para futuras recomendações e utilização como progenitores em programas de melhoramento (QUEROL, 1993).

$\mathrm{O}$ presente trabalho teve como objetivo analisar a diversidade genética entre acessos tradicionais de mandioca da coleção da UNEMAT, via caracteres morfoagronômicos.

\section{MATERIAL E MÉTODOS}

O presente trabalho foi realizado com 21 acessos tradicionais de mandioca da coleção da Universidade do Estado de Mato Grosso - UNEMAT, campus Cáceres, MT. A coleção está localizada na Empresa Matogrossense de Pesquisa, Assistência e Extensão Rural (EMPAER) de Cáceres - MT.

Com altitude de 118 metros, o clima característico da região, segundo a classificação de Köppen, é do tipo tropical, quente, úmido e inverno seco (Awa), com período de chuvas de outubro a março e seca de abril a setembro (NEVES et al., 2011). O solo é classificado como Argissolo Vermelho Amarelo Eutrófico chernossólico, de textura média argilosa (ARANTES et al., 2012).

Os acessos tradicionais de mandioca avaliados foram os seguintes: Amarelinha, Branquinha, Cacau 9 meses, Cacau Branca, Cacau Vermelha, Cuiuda, Liberata 0306, Liberatão 0507, N.I. 01- 0718, N.I. 01- 2715, N.I. 02- 0818, N.I. 022816, N.I. 06- 0202, N.I. 10- 0501, N.I. 16- 1503, Polpa Branca, Pretinha, Rondônia, Roxa, Sinop e Vermelha.

Foram avaliados 13 características quantitativas dos acessos de mandioca, conforme a metodologia proposta por Fukuda; Guevara, (1998), sendo: comprimento médio do lóbulo foliar (CL); largura média do lóbulo foliar (LL); comprimento médio do pecíolo (CP); altura média de plantas (AP); altura média da primeira ramificação (AR); comprimento médio das raízes $(\mathrm{CR})$; diâmetro médio da raiz (DR); peso médio da raiz (PR); contagem do número de raízes sadias por planta $(\mathrm{RS})$; número médio de raízes $(\mathrm{NR})$; peso em água (PA); matéria seca (MS) e teor de amido (TA).

Para características de altura e comprimento foi utilizada uma fita métrica. As características, como diâmetro e peso foram realizadas com o auxílio de um paquímetro e uma balança de prato, respectivamente. O teor de amido foi obtido através do método da balança hidrostática, a partir de uma amostra de $3 \mathrm{~kg}$ de raízes tuberosas, conforme proposto por Grosmann; Freitas, (1950). Para a obtenção das médias no presente estudo foram avaliadas cinco plantas após doze meses de plantio.

As médias fenotípicas dos caracteres morfoagronômicos quantitativos foram utilizadas para estimar a Distância Euclidiana que é dada por:

$$
d_{i i^{\prime}}=\sqrt{\sum_{j}\left(X_{i j}-X_{i^{\prime} j}\right)^{2}}
$$

em que: dii': distância euclidiana entre os genótipos i e i';Xij: média do $i$-ésimogenótipo, em relação ao $j$-ésimocaráter.

Desta forma foi gerada uma matriz de dissimilaridade referente às características morfoagronômicas quantitativas.

Aplicou-se o Método de Agrupamento Hierárquico de Ligação Média Entre Grupos (UPGMA) para estimar os possíveis agrupamentos dos acessos. As análises estatísticas foram efetuadas com o auxílio do programa computacional Genes (CRUZ, 2013).

\section{RESULTADOS}

De acordo com os dados das medidas de dissimilaridade genética (Tabela 1) em relação às 13 características avaliadas e estimadas através da Distância Euclidiana $\left(\mathrm{d}_{\mathrm{ii}}\right)$, foi possível observar que o acesso Sinop aparece com maior frequência em relação à formação dos pares mais dissimilares. Sendo que os mais divergentes foram às combinações Sinop x Liberatão $0507\left(\mathrm{~d}_{\mathrm{ii}},=8,79\right)$, apresentando-se como mais divergentes 
entre si, seguidos de Sinop x N.I. 06- $0202\left(\mathrm{~d}_{\mathrm{ii}},=8,49\right)$. Revelando que o acesso Sinop poderia ser utilizado como parental em futuros programas de melhoramento genético visando a melhoria de características agronômicas.

$\mathrm{Na}$ formação dos pares mais similares, ou seja, àqueles que mais se aproximam geneticamente, foram às combinações Rondônia x N.I. 10 -0501 ( $\left.\mathrm{d}_{\mathrm{ii}}{ }^{\prime}=1,26\right)$, seguidos de Vermelha $\mathrm{x}$ Amarelinha $\left(\mathrm{d}_{\mathrm{ii}}{ }^{\prime}=1,73\right)$.

Analisando o dendrograma gerado pelo método de agrupamento Hierárquico UPGMA (Figura 1), é possível evidenciar a existência de variabilidade genética, considerando um corte significativo gerado pelo programa Genes de $75 \%$ de distância genética, podendo verificar a formação de sete grupos distintos. O primeiro grupo é composto por 12 acessos, formado pelo N.I. 10 - 0501, Rondônia, Cacau 9 meses, Branquinha, Cacau Vermelha, Amarelinha, Vermelha, Cacau Branca, Cuiuda, Liberata 0306, N.I. 16 - 1503, N.I. 01 - 2715.

Os acessos que foram alocados no Grupo I, (57,14\% do total), compreendem acessos com características morfoagronômicas próximas, revelando grande afinidade entre a maioria dos materiais avaliados que se encontram na coleção. O Grupo II é composto pelo acesso N.I. 06 - 0202 (4,76\%). O Grupo III é composto pelo acesso Liberatão 0507
$(4,76 \%)$. No Grupo IV foram alocados os acessos N.I. 01 0718, N.I. 02- 0818, Roxa e Pretinha (19,04\%). Nos Grupos V, VI e VII, foram alocados somente um acesso, sendo eles, Sinop, N.I. 02-2816 e Polpa Branca, respectivamente, correspondendo $4,76 \%$ do total de acessos em cada grupo (Figura 1).

O caractere que contribuiu para que os acessos do Grupo IV divergissem dos demais, está na diferença com relação à característica AR (Altura média da primeira ramificação), pois cinco dos seis materiais deste grupo possuem hábito de crescimento ereto, diferente dos materiais alocados nos demais Grupos, os quais possuem hábito de crescimento dicotômico, tricotômico ou tetracotômico.

O dendrograma gerado pelo UPGMA corrobora também com os valores de dissimilaridade gerados pela Distância Euclidiana, pois o Grupo I contém os acessos com maior similaridade (Rondônia x N.I. 10 - $0501\left(\mathrm{~d}_{\mathrm{ii}}=1,26\right)$, sendo que a maior divergência se apresenta entre acessos de grupos diferentes Sinop x Liberatão $0507\left(\mathrm{~d}_{\mathrm{ii}}\right.$ = 8,79).O coeficiente de correlação cofenética do dendrograma neste estudo obteve um valor de $(\mathrm{r}=0,74)$, sendo significativo a $1 \%$ de probabilidade, segundo o teste $\mathrm{T}$, conferindo confiabilidade na avaliação visual.

Tabela 1. Medidas de dissimilaridade entre os 21 acessos de mandioca, em relação a 13 características, com base na Distância Euclidiana (dii'), Cáceres-MT (2011).

Table 1. Measures of dissimilarity among the 21 accessions of cassava, in relation to 13 characteristics, based on Euclidian Distance ( $\mathrm{d}_{\mathrm{ii}}$ ), Cáceres-MT (2011).

\begin{tabular}{|c|c|c|c|c|c|c|c|c|c|c|c|c|c|c|c|c|c|c|c|c|c|}
\hline Ac. & 1 & 2 & 3 & 4 & 5 & 6 & 7 & 8 & 9 & 10 & 11 & 12 & 13 & 14 & 15 & 16 & 17 & 18 & 19 & 20 & 21 \\
\hline 1 & 0,00 & 5,39 & 5,29 & 4,06 & 5,05 & 3,67 & 3,00 & 4,18 & 5,17 & 3,98 & 6,09 & 4,08 & 5,35 & 3,56 & 2,77 & 6,25 & 4,95 & 5,53 & 3,04 & 8,31 & 1,73 \\
\hline 2 & & 0,00 & 4,16 & 3,86 & 2,87 & 2,76 & 4,15 & 6,33 & 5,19 & 4,37 & 5,60 & 6,93 & 3,74 & 4,15 & 4,35 & 6,43 & 5,45 & 6,81 & 4,09 & 6,61 & 5,27 \\
\hline 3 & & & 0,00 & 5,16 & 3,20 & 4,41 & 3,97 & 6,69 & 4,01 & 4,38 & 5,01 & 6,49 & 5,00 & 2,84 & 4,34 & 5,78 & 3,97 & 4,75 & 2,72 & 4,75 & 5,00 \\
\hline 4 & & & & 0,00 & 4,58 & 2,00 & 2,50 & 5,45 & 5,59 & 2,87 & 6,28 & 5,86 & 5,56 & 4,77 & 3,41 & 4,36 & 5,80 & 6,83 & 4,09 & 7,15 & 4,19 \\
\hline 5 & & & & & 0,00 & 3,72 & 4,51 & 4,75 & 3,57 & 3,46 & 3,67 & 6,71 & 4,51 & 2,70 & 4,29 & 6,32 & 4,92 & 5,22 & 3,14 & 5,92 & 5,23 \\
\hline 6 & & & & & & 0,00 & 2,37 & 5,22 & 5,15 & 3,41 & 5,92 & 5,31 & 3,87 & 3,70 & 2,38 & 5,12 & 5,29 & 6,06 & 3,28 & 6,98 & 3,89 \\
\hline 7 & & & & & & & 0,00 & 5,76 & 4,85 & 3,67 & 5,98 & 4,07 & 5,09 & 3,80 & 2,02 & 4,94 & 4,22 & 5,41 & 3,04 & 6,57 & 3,07 \\
\hline 8 & & & & & & & & 0,00 & 5,03 & 4,09 & 4,81 & 6,35 & 6,77 & 4,38 & 4,99 & 7,13 & 6,70 & 5,82 & 4,71 & 8,79 & 5,27 \\
\hline 9 & & & & & & & & & 0,00 & 4,35 & 1,83 & 5,61 & 6,30 & 3,33 & 5,03 & 6,11 & 3,08 & 3,11 & 3,77 & 4,67 & 5,36 \\
\hline 10 & & & & & & & & & & 0,00 & 4,85 & 6,62 & 5,60 & 3,51 & 4,12 & 4,72 & 5,63 & 6,08 & 2,96 & 6,82 & 4,18 \\
\hline 11 & & & & & & & & & & & 0,00 & 6,67 & 7,10 & 4,18 & 5,94 & 6,92 & 4,37 & 4,09 & 4,82 & 5,25 & 6,47 \\
\hline 12 & & & & & & & & & & & & 0,00 & 6,97 & 5,44 & 3,63 & 7,66 & 4,76 & 4,61 & 5,38 & 8,17 & 4,95 \\
\hline 13 & & & & & & & & & & & & & 0,00 & 4,07 & 4,34 & 8,01 & 6,70 & 7,08 & 4,00 & 8,49 & 5,43 \\
\hline 14 & & & & & & & & & & & & & & 0,00 & 3,22 & 6,28 & 4,25 & 3,99 & 1,26 & 6,39 & 3,95 \\
\hline 15 & & & & & & & & & & & & & & & 0,00 & 6,11 & 4,96 & 4,98 & 2,90 & 7,40 & 3,65 \\
\hline 16 & & & & & & & & & & & & & & & & 0,00 & 5,96 & 6,99 & 5,69 & 5,61 & 5,69 \\
\hline 17 & & & & & & & & & & & & & & & & & 0,00 & 3,68 & 4,28 & 4,54 & 4,58 \\
\hline 18 & & & & & & & & & & & & & & & & & & 0,00 & 4,63 & 5,58 & 6,03 \\
\hline 19 & & & & & & & & & & & & & & & & & & & 0,00 & 6,48 & 3,16 \\
\hline 20 & & & & & & & & & & & & & & & & & & & & 0,00 & 7,91 \\
\hline 21 & & & & & & & & & & & & & & & & & & & & & 0,00 \\
\hline
\end{tabular}

I' (1) Amarelinha; (2) Branquinha; (3) Cacau 9 meses; (4) Cacau Branca; (5) Cacau Vermelha; (6) Cuiuda; (7) Liberata 0306; (8) Liberatão 0507; (9) N.I. 010718; (10) N.I. 01-2715; (11) N.I. 02-0818; (12) N.I. 02-2816; (13) N.I. 06-0202; (14) N.I. 10-0501; (15) N.I. 16-1503; (16) Polpa Branca; (17) Pretinha; (18) Roxa; (19) Rondônia; (20) Sinop; (21) Vermelha.

\section{DISCUSSÃO}

Em estudo realizado por Vieira et al., (2008) com acessos açucarados e não açucarados de mandioca, através de características quantitativas, revelou que um dos acessos estudados se divergiu dos demais em três das nove características avaliadas. Segundo o mesmo autor, a importância do estudo de características quantitativas está na avaliação de acessos, uma vez que, refletem o real potencial produtivo possibilitando sua utilização de forma direta ou no melhoramento genético.

Segundo Schawinski (2006), em estudo realizado na região de Cáceres, revela que os produtores não possuem o hábito de introduzir materiais que venha de outros locais que não seja da própria região, sendo as manivas-sementes adquiridas de propriedades vizinhas ou próximas, diminuindo a variabilidade e dificultando a nomenclatura dos acessos. Tais resultados explicam a grande similaridade genética entre os 
acessos avaliados. Fato este também comprovado por Morais (2008), que constatou uma grande proximidade genética entre acessos de mandioca na região de Cáceres.

A utilização do método hierárquico de UPGMA para estudo da variabilidade genética possibilitou a formação de vários grupos, sendo um deles formado por um maior número de acessos. Estudo realizado por Silva et al., (2011) sobre divergência genética em cana-de-açúcar utilizando o UPGMA, obteve-se a formação de dois grandes grupos, onde, o grande número de genótipos em um mesmo grupo, revela uma base genética restrita entre eles. Resultados semelhantes foram observados por Campos et al., (2010), caracterizando e quantificando a divergência genética entre 53 acessos de mandioca, por meio de 28 descritores morfológicos, sendo o primeiro grupo formado por um grande número de acessos, e os demais grupos formados apresentaram menor número de acessos.
O dendrograma gerado pelo UPGMA corrobora também com os valores de dissimilaridade gerados pela Distância Euclidiana, pois o Grupo I contém os acessos com maior similaridade (Rondônia x N.I. 10- $0501\left(\mathrm{~d}_{\mathrm{ii}},=1,26\right)$, sendo que a maior divergência se apresenta entre acessos de grupos diferentes Sinop x Liberatão $0507 \quad\left(\mathrm{~d}_{\mathrm{ii}},=8,79\right)$. Para Vendramini et al., (2011) o UPGMA oferece uma apresentação mais detalhada, sendo possível a concepção dentro dos grupos daqueles acessos que possuem maior afinidade, possibilitando visualizar as distâncias dentro de um determinado grupo.

O coeficiente de correlação cofenética do dendrograma apresentou confiabilidade dos resultados na avaliação visual. Vieira et al., (2013) caracterizando e estimando a variabilidade genética entre acessos de mandioca de mesa, obtiveram valor semelhante, revelando considerável ajuste entre a representação gráfica e a matriz.

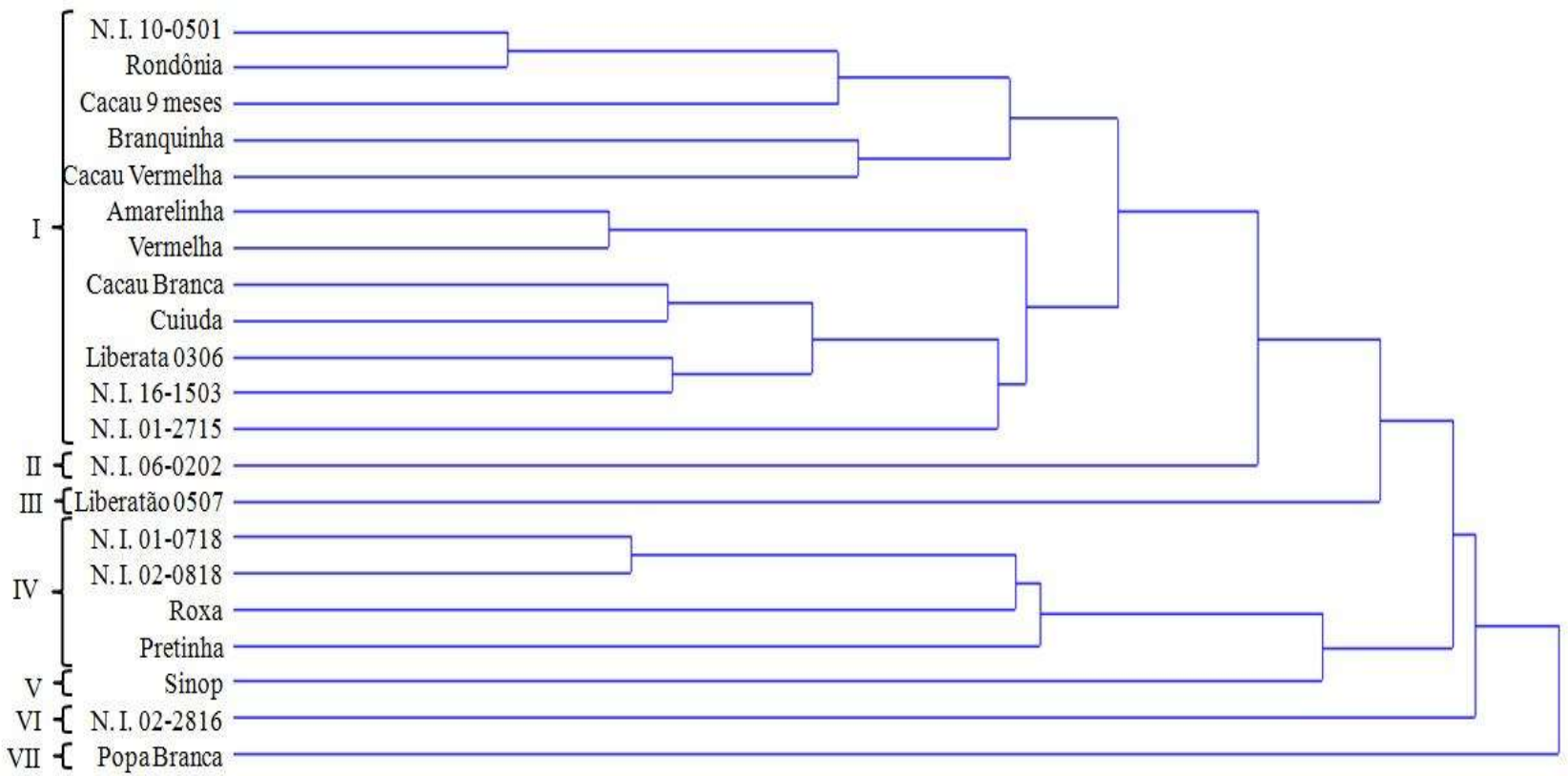

\begin{tabular}{llllllllll}
\hline & 10 & 20 & 30 & 40 & 50 & 60 & 70 & 80 & 90
\end{tabular}

Figura 1.Dendrograma representativo do agrupamento, estimado através de 13 características quantitativas, em 21 acessos de mandioca da coleção da UNEMAT, pelo Método UPGMA (Cáceres - MT, 2011).

Figure 1. Dendrogram representative of the grouping, estimated through quantitative characteristics, of 21 accessions of cassava from the UNEMAT collection, by the UPGMA Method (Cáceres - MT, 2011).

\section{CONCLUSÕES}

Há divergência genética entre os acessos de mandiocas avaliados da coleção da Unemat, onde os descritores morfoagronômicos utilizados no trabalho foram eficientes na diferenciação dos acessos.

Os acessos NI 02-2816, Poupa Branca e Sinop, apresentaram maior dissimilaridade entre os demais acessos analisados, sendo os parentais mais promissores para futuro cruzamento, onde a melhor combinação para cruzamento está entre os acessos Sinop x Liberatão 0507 por apresentar maior distância genética.

\section{REFERÊNCIAS}

ABREU, M. L. de; BICUDO, S. J.; BRACHTVOGEL, E. L.; CURCELLI, F.; AGUIAR, E. B. Interação genótipo ambiente na cultura da mandioca. Revista Raízes e Amidos Tropicais, Botucatu, v. 4, p. 44-54, 2008.
AMARAL, L.; JAIGOBIND, A. G. A.; JAISINGH, S. Processamento da mandioca. Paraná: Instituto de Tecnologia do Paraná - TECPAR, 2007. 48 p. (Dossiê Técnico)

ARANTES, E. M.; CREMON, C.; LUIZ, M. A. C. Alterações dos atributos químicos do solo cultivado no sistema orgânico com plantio direto sob diferentes coberturas vegetais. Revista Agrarian, Dourado, v. 5, n. 12, p. 4754, 2012.

CAMPOS, A. L. de; ZACARIAS, A. J.; COSTA, D. L.; NEVES, L. G.; BARELLI, M. A. A.; SOBRINHO, S. P.; LUZ, P. B. da. Avaliação de acessos de mandioca do banco de germoplasma da UNEMAT Cáceres - Mato Grosso. Revista Trópica - Ciências Agrárias e Biológicas, Boa Vista, v. 4, n. 2, p. 44-54, 2010. 
CONCEIÇÃO, A. J. da. A mandioca. Cruz das Almas: UFBA/Embrapa-CNPMF/BNB/Brascan Nordeste, 1983. $823 \mathrm{p}$.

COSTA, M. R.; CARDoso, E. R.; OHAZE, M. M. M. Similaridade genética de cultivares demandioca (Manihot esculenta) por meio de marcadores RAPD. Ciência e Agrotecnologia, Lavras, v. 27, n. 1, p. 158-164, 2003. DOI: 70542003000100019

CRUZ, C. D. GENES - a software package for analysis in experimental statistics and quantitative genetics. Acta Scientiarum, Paraná, v. 35, n. 3, p. 271-276, 2013. DOI: http://dx.doi.org/10.4025/actasciagron.v35i3.21251

FAO_ Food and Agricultural commodities production. Faostat database gateway. 2013. Disponível em: $<$ http://faostat3.fao.org/download/Q/QC/E $>$. Acesso em: 08 jun 2015

FAO_ Food and Agricultural commodities production Faostat database gateway. 2016. Disponível em: $<$ http://www.fao.org/faostat/en/\#data/QC $>$. Acesso em: 13 ago 2018.

FUKUDA, W. A. G.; GUEVARA, C. L. Descritores morfológicos e agronômicos para a caracterização de mandioca (Manihot esculenta Crantz). Cruz das Almas: EMBRAPA - CNPMF, 1998. 38 p.

GROSMANN, J.; FREITAS, A. G. Determinação do teor de matéria seca pelo método de peso específico em raízes de mandioca. Revista Agronômica, v. 14, n. 160-162, p. 7580,1950

MORAIS, J. A. de. Divergência genética entre acessos de mandioca-de-mesa na região de Cáceres - MT. 2008. 26 f. Dissertação (Monografia) - Universidade do Estado de Mato Grosso, Cáceres, 2008

NEVES, S. M. A. S.; NUNES, M. C. M.; NEVES, R. J. Caracterização das condições climáticas de Cáceres/MTBrasil, no período de 1971 a 2009: subsídio às atividades agropecuárias e turísticas municipais. Boletim Goiano de geografia, Goiânia, v. 31, n. 2, p. 55-68, 2011. DOI: http://dx.doi.org/10.5216/bgg.V31i2.16845

QUEROL, D. Recursos genéticos, nosso tesouro esquecido, abordagem técnica e sócio econômica. Rio de Janeiro: ASPTA, 1993. $206 \mathrm{p}$

SCHAWINSKI, E. C. Avaliação de acessos de mandioca (Manihot esculenta Crantz.) com o uso de variáveis multicategóricas no município de Cáceres - MT. Cáceres, 2006, 40p. Dissertação (monografia). Universidade do Estado de Mato Grosso.

SILVA, G. C.; OLIVEIRA, F. J. de; FILHO, C. J. A.; NETO, D. E. S.; MELO, L. J. O. T. de. Divergência genética entre genótipos de cana-de-açúcar. Revista Brasileira de Ciências Agrárias, Recife, v. 6, n. 1, p. 52-58, 2011. DOI: http://dx.doi.org/10.5039/agraria.v6i1a848

SOUZA, L. S.; FIALHO, J. F. Cultivo de Mandioca para Região de Cerrado. Cruz da Almas: Embrapa Mandioca e Fruticultura, 2003. (Sistemas de Produção, 8)

VENDRAMINI, J. M.; NEVES, L. G.; BARELLI, M. A. A.; ELIAS, J. C. F.; LUZ, P. B. da. Otimização do uso dos descritores morfoagronômicos de mandioca em análise multivariada. Revista Ciência Agronômica, Fortaleza, v. 12 , n. 4, p. 906-913, 2011. DOI: http://dx.doi.org/10.1590/S1806-66902011000400012

VIEIRA, E. A.; FIALHO, J. de F.; FALEIRO, F. G.; BELLON, G.; FONSECA, K. G. DA; SILVA, M. S.; PAULA-MORAES, S. V. de; CARVALHO, L. J. C. B. Caracterização fenotípica e molecular de acessos de mandioca de indústria com potencial de adaptação às condições do Cerrado do Brasil Central. Semina Ciências Agrárias, Londrina, v. 34, p. 567-582, 2013. DOI: http://dx.doi.org/10.5433/1679-0359.2013v34n2p567

VIEIRA, E. A.; FIALHO, J. F.; FALEIRO, F. G.; BELLON, G.; FONSECA, K. G. da; CARVALHO, L. J. C. B.; SILVA, M. S.; MORAES, S. V. P.; FILHO, M. O. S. S.; SILVA, K. N. Divergência genética entre acessos açucarados e não açucarados de mandioca. Pesquisa Agropecuária Brasileira, Brasília, v. 43, n. 12, p. 1707 1715,2008

YAMAMOTO, P. Y. Interação genótipo $\mathbf{x}$ ambiente na produção e composição de óleos essenciais de Lippia Alba (Mill.) N. E. Br. 2006. 56f. Dissertação (Mestrado em Genética e Melhoramento) - Instituto Agronômico de Campinas, Campinas, 2006.

ZUIN, G. C.; VIDIGAL FILHO, O. S.; KVITSCHAL, M. V.; VIDIGAL, M. C. G.; COIMBRA G. K. Divergência genética entre acessos de mandioca-de-mesa coletados no município de Cianorte, região Noroeste do Estado do Paraná. Semina Ciências Agrárias, Londrina, v. 30, n. 1, p. 21-30. 2009. DOI: http://dx.doi.org/10.5433/1679$0359.2009 \mathrm{v} 30 \mathrm{n} 1 \mathrm{p} 21$ 